\title{
IMAGINACIÓN VISIONARIA Y CRISIS MODERNAS: BLAKE, EMERSON Y WHITMAN
}

\author{
Andrés Ferrada Aguilar \\ Universidad de Playa Ancha, Valparaíso, Chile \\ Universidad de Chile, Santiago de Chile \\ aferrada@upla.cl
}

\section{RESUMEN/ ABSTRACT}

Este trabajo intenta articular las correspondencias entre la imaginación visionaria y las fisuras que impone una modernidad de corte industrial y protestante en una selección de poemas y escritos referenciales de William Blake, R. W. Emerson y Walt Whitman. A partir de la indagación de un mundus imaginalis se establecen nexos entre este espacio integrativo y su figuración en la escritura de los autores mencionados. Surgen así visiones poéticas que dialogan, simultáneamente, con un espacio imaginal y su necesaria contraparte, una cultura moderna desencantada.

Palabras Clave: imaginación visionaria, espacio imaginal, desencanto, romanticismo, transcendentalismo.

\section{VISIONARY IMAGINATION AND MODERN CRISES: BLAKE, EMERSON AND WHITMAN}

This study intends to articulate correspondences between the visionary imagination and the fissures produced by an industrial and protestant modernity in a selection of poems and referential writings by William Blake, $R$. W. Emerson, and Walt Whitman. The relationship between the integrative nature of a mundus imaginalis and its figuration in the works of the poets is also relevant. As a result, we can better appreciate poetic visions that converse, simultaneously, with an imaginal site and its necessary counterpart, a disenchanted modern culture.

KEYWORDS: Visionary imagination, imaginal site, disenchantment, Romanticism, Transcendentalism.

Recepción: 03/09/2019

Aprobación: 01//12/2019 


\section{INTRODUCCIÓN}

Uno de los aspectos más sobresalientes del romanticismo en lengua inglesa es la relevancia que concede a la imaginación visionaria, al punto de convertirla en una vía cognoscente igualmente válida, e incluso superior, al racionalismo empírico. Interviene directamente en la génesis de la creación poética y, al mismo tiempo, interroga la legitimidad de las epistemes eurocéntricas. Nuestro objeto de estudio considera esta imaginación visionaria, tal y como la conciben William Blake, Ralph Waldo Emerson y Walt Whitman, en diálogo con un espacio imaginal y con las crisis del tiempo moderno. Desde aquí abordaremos tres momentos asociados al romanticismo inglés y transatlántico, acentuando no solo sus convergencias, sino también divergencias. Para ello, examinaremos un conjunto de poemas y ensayos que, en diferentes sentidos, desafían el binarismo sobre el cual se constituye la cultura moderna de los siglos XVIII y XIX. Entre otros, destacamos el segundo libro profético de Milton y "Londres" de Blake; "El poeta" y "Naturaleza" de Emerson; y Canto a mí mismo y Golpes de tambor de Whitman.

Los trabajos de estos autores relevan temas vinculados a un sentido de crisis. Circulan iterativos en las imágenes y metáforas de sus poemas, como también en sus escritos referenciales. Son, como señala Max Weber, índices de una interpretación desencantada de la realidad, característicos de un racionalismo moderno de corte iluminista. Proponemos que estos temas se problematizan en contacto con un espacio imaginal que alienta la actividad imaginativa, adscrita al devenir visionario en la obra de los autores. Este espacio adquiere figuraciones diversas en la escritura visionaria. Aun así, su presencia recuerda que la razón y la secularidad del pensamiento son fragmentos escindidos de un mundus imaginalis, donde el logos y el mito solidarizan al punto de la indiferenciación. Ahora bien, la imaginación en los trabajos de estos poetas no solo nos remite a un espacio imaginal, sino que, a partir de esa figuración, apreciamos una contraparte moderna, encarnada en las fisuras de un mundo desencantado. La experiencia visionaria, piedra angular de una poética de ruptura y rehabilitación, transparenta así crisis fundamentales en los trabajos de Blake, Emerson y Whitman que aluden a las ilusiones del mundo sensible, la percepción de un tiempo degradado y la celebración de una comunidad amenazada, respectivamente. 
Un concepto relevante en este estudio es el de mundus imaginalis, que Henry Corbin articula a partir de teosofías iraníes ${ }^{1}$, saberes que Harold Bloom descarta como vía de acceso para la interpretación de Beulah, o el eterno imaginativo, en la obra de Blake. Corbin, en cambio, estimó necesario introducir estos saberes en la academia con el fin de complejizar el entendimiento de la imaginación y la actividad creadora. Con ello, sus trabajos promueven un descentramiento que interroga las narraciones epistémicas construidas a partir de un eurocentrismo ${ }^{2}$. Este desajuste se realiza desde un espacio imaginal "ontológicamente tan real como el de los sentidos y el intelecto. Este mundo está constituido por su propia facultad perceptiva, un poder imaginativo que posee una función cognitiva y un valor noético tan efectivos como la percepción sensitiva o la intuición intelectual" (Corbin 5). El autor se apresura a clarificar un aspecto, presente también en las poéticas de los románticos ingleses: "Debemos ser cuidadosos de no confundir este [mundo] con el tipo de imaginación que el hombre moderno relaciona con la 'fantasía', y que entiende simplemente como una secuencia de imaginaciones" (5). Otro elemento de este mundo es su capacidad integrativa, membrana que une lo terrenal y lo espiritual. Al respecto, cabe acentuar que lo "imaginal es el cronotopo en el que actúan o se recogen las implicaciones y las incidencias de la ecología en la gnoseología, y viceversa" (Rodríguez 39).

En el contexto de nuestra propuesta, lo imaginal insta, por un lado, a explorar sus principios integrativos/creativos en la imaginación visionaria de los poetas y, por otro, a advertir la emergencia de su radical contrapartida, un mundo "previsible". Esta otra visión, tan importante como la imaginal en la fragua de la imaginación romántica, se asocia a un desencantamiento moderno que Weber explica como la progresiva "intelectualización y racionalización”

Un texto seminal que permite a Corbin explorar la imaginación más allá de las fronteras de una episteme occidental es El arcángel carmesí, escrito persa del siglo XII del sheikh Sohrawardi. Esta obra reúne cuentos visionarios y narraciones de iniciación espiritual en torno a experiencias gnósticas (Corbin 2).

Sobre este punto, Corbin subraya que la "Imaginación activa o agente no es en absoluto un instrumento que provenga de lo imaginario, de lo irreal, lo mítico o la ficción. Por eso era absolutamente necesario encontrar un término que diferenciara radicalmente entre lo imaginario y el intermundo de la Imaginación, tal como se presenta a nuestros metafísicos iraníes" (Cuerpo espiritual 21). Desde aquí, el desafío que surge para la investigación de la imaginación romántica radica en contraponerla a la luz de otros aportes, como el de las teosofías no occidentales, sin desestimar su contexto de producción, las mitologías idiosincrásicas y las lecturas que los poetas hacen del mundo desencantado, o el curso de la modernidad. 
(92) de la actividad humana. Este proceso implica "la creencia de que en el momento que se quiera, es posible llegar a saber, por consiguiente, que no existen poderes ocultos e imprevisibles alrededor de nuestra existencia" (92). En la cosmografía blakeana esta creencia recrudece en Urizen, dominio de la razón. Emerson y Whitman, en tanto, la identifican con una cultura letrada plagada de "espectros". Comprender una de las fases de la modernidad desde la previsibilidad permite apreciar la restitución del "encanto" no solo en el gesto escritural, o en la creación de la obra sensible, sino como parte de un ethos (pre)romántico reflexivo, atento a los quiebres que ocasionan en el tejido comunitario el cientifismo, la urbanización y la modernización económica.

El romanticismo se manifiesta de un modo complejo, y si bien es posible observar afinidades entre escritores y obras, también percibimos divergencias, no solo entre Blake y los transcendentalistas norteamericanos, sino entre Emerson y Whitman. Como indica Octavio Paz, Blake tensiona el papel de la imaginación, al punto de que "el culto a la naturaleza, que es uno de los rasgos de la poesía romántica, no aparece en su obra" (61). Whitman, en cambio, transforma ese culto en fascinación cotidiana con los paisajes; el espacio natural se convierte en un santuario al aire libre. A pesar de estas diferencias, quisiera relevar dos principios que se desplazan en los trabajos de estos autores, generando una dialéctica entre lo imaginal y lo racional. Uno, el analógico, o "la correspondencia entre todos los seres y los mundos" (Paz 63), que anima el espacio imaginal y el encantamiento del mundo. Otro, el irónico, o anulación de las correspondencias, "que se llama, en el poema: ironía, y en la vida: mortalidad. La poesía moderna es la conciencia de esa disonancia dentro de la analogía" (Paz 64, énfasis suyo). En el desarrollo de este estudio asociaremos esta ruptura con las crisis por las que atraviesan los trabajos de Blake, Emerson y Whitman, asociadas al ámbito de la experiencia (en sentido blakeano), la percepción de un tiempo fisurado y la fragmentación comunitaria, respectivamente.

Concordando con la idea de que "el romanticismo fue un movimiento literario, pero asimismo fue una moral, una erótica y una política" (Paz 65), sostenemos que la imaginación visionaria, incluso en sus apogeos blakeanos, fue siempre consciente de su lugar en el mundo, y de su cometido. Desde este ángulo, y percibiendo un despliegue relevante de esa visión en la literatura romántica, no es difícil constatar los enlaces entre inocencia y experiencia; encantamiento y racionalización; unicidad y fragmentación. Así, el romanticismo, y debido a las decisivas revoluciones de la época, interpreta 
el trance visionario precisamente como una transición entre el mundo sensible y su perennidad en el espacio de la imaginación.

Para Peter Dinzelbacher, de acuerdo a su concepción de la literatura visionaria en Europa de la Edad Media, "la experiencia visionaria está necesariamente relacionada -en primer lugar-con el sueño o con el éxtasis" (Góngora, "Escritura" 376). Observamos que estas condiciones, en particular el sueño, prevalecen en los textos que analizaremos. Retienen el germen visionario, pero lo transforman a partir de su fricción con una cultura moderna. El éxtasis, por ejemplo, significará “estar fuera de sí", pero con un fin distinto al de la visión mística o religiosa en la tradición cristiana. Esta suspensión del ego, que Blake y Whitman asocian al goce sexual, permite que el poeta se adentre en el mundo de la imaginación creado por él mismo. Una vez allí, refuerza su consciencia histórica y secular. El visionario moderno es así un sujeto bifronte que habita dos espacios distintivos, pero intercomunicados. Jano, el dios romano de las aperturas y los portales, ofrece una decidora imagen de este visionario en el contexto de la modernidad anglo-americana.

Entre los estudios recientes que han abordado el problema de la imaginación visionaria en la obra de Blake, y sus nexos con movimientos afines, como el simbolismo y el surrealismo, destaco Visiones de William Blake, de Daniela Picón. Considerando la idea blakeana de la imaginación, que Kathleen Raine compara con las exégesis de textos visionarios iraníes por parte de Henry Corbin, Picón advierte "sugerentes afinidades entre el mundus imaginalis y Beulah, la región de la noche y los sueños en el mundo visionario de Blake" (134). Nuestra propuesta, por su parte, aborda la relación entre la imaginación visionaria y lo imaginal, con énfasis en el modo en que la creación de este espacio está vinculada con la experiencia de un ciclo espacio-temporal desencantado. Debido a que intentaremos articular la expresión de estas vertientes imaginativas en un contexto anglo-americano, este estudio encarece otras aristas románticas, situadas extramuros del canon (pre)romántico inglés.

Una serie de intentos han leído este romanticismo a la luz de otros sitios geográfico-literarios, como Los hijos del limo (1972). Impulsados por la academia estadounidense, estudios más recientes como el de Virginia Jackson, "American Romanticism, Again" (2016), también encarecen relaciones de sentido entre el romanticismo europeo y, en su caso, el trascendentalismo emersoniano. Argumenta la autora que "la idea de una poesía Americana fue y continúa siendo inventada" (324), y debido a que esa invención aún no ha sido descrita, existe una tendencia a acentuar su originalidad en desmedro de sus vínculos transatlánticos y románticos. Sea como fuere, en lugar de visualizar 
afluentes americanos del romanticismo inglés, advertimos expresiones, atendiendo a que las poéticas de Emerson y Whitman, si bien influidas por esa tradición, sugieren desviaciones inéditas. En especial si apreciamos la eficacia del paisaje americano como umbral para una imaginación visionaria sui generis. Y más aún, al notar que este paisaje deviene, en sí mismo, visión. Una visión que, insistimos, resulta inseparable de un sentido de crisis.

\section{BLAKE: LA PLACENTA IMAGINAL Y EL GRITO DE LA EXPERIENCIA}

En el mundo eterno existen realidades eternas de todo lo que vemos reflejado en el espejo vegetal de la naturaleza. William Blake, "El bien y el mal"

En el convulsionado espacio moderno del siglo XVIII, caracterizado por conceptuaciones unívocas, confirmamos lo arduo que significó para William Blake no solamente crear, sino legitimar sus creaciones. Incluso hoy, si el fin no es reducir, abordar su obra resulta desafiante. Seguimos, sin duda, a merced de un positivismo que nos conmina a poner las cosas en su sitio. Y, desde aquí, trabajamos sobre el supuesto de realidades aprehensibles. En la obra de Blake asistimos a una visión donde el pensamiento totalizante y categorial se difumina, originando una deriva contramoderna. Su poesía, sin otro argumento que la fecundidad de la imagen, desnaturaliza el racionalismo de la época, anticipándose a la crítica cultural que se vislumbra en los ensayos de P. B. Shelley, o R. W. Emerson en Nueva Inglaterra.

Desde un punto de vista formal, la "estructura en serie" de las planchas de sus libros iluminados permite a Blake alterar "la ordenación secuencial de sus obras, las que raramente manifiestan una ordenación lógica. Por esta razón la crítica las ha descrito como 'fragmentos de una unidad' que deben ser reconstruidas por los lectores" (Picón, Visiones 78). En conjunto, sus obras no sucumben a la causalidad de los objetos sensibles y, desde aquí, se hace complejo pesquisar tramas de sentido, o los enlaces que unen a varias composiciones entre sí. Algo similar ocurre al interior de trabajos particulares, donde el fuerte intercambio de elementos gráficos y textuales favorece desajustes jerárquicos. Las palabras y las imágenes devienen medios 
expresivos que, fusionados, redicen distinciones icónicas o conceptuales, trascendiendo el orden categorial.

$\mathrm{Si}$, como plantea Tzvetan Todorov, el retrato en el siglo XVIII se convierte en una síntesis pictórica de los valores del sujeto cartesiano, la obra de Blake puede leerse como una alteración estética y, sobre todo, "filoimaginal" de aquel orden ${ }^{3}$. No solo lo contradice, sino que convoca la existencia de un mundus imaginalis. Constituye esta digresión una lúcida crítica de la modernidad que, coherente con un espíritu imaginativo, no descansa en un sistema de pensamiento, sino en una praxis artística. Al respecto, Bloom ha dicho que Blake, Coleridge y Wordsworth, y posteriormente Shelley, Byron y Keats, convivieron en un mundo que carecía de un lenguaje adecuado para la imaginación, lo que redundó en la exaltación de una consciencia según la cual una verdadera visión de la realidad se sustenta en la imaginación (Visionary xiv). Veamos ahora la forma que adopta este mundus en el trabajo de William Blake.

La inocencia, tal como la entiende el poeta, no es carencia o ignorancia. Constituye la certeza de habitar un ámbito del ser sin distinciones. En el segundo libro profético de Milton, Blake describe esta habitación como "un lugar donde los Contrarios son igualmente Verdaderos:/ Este lugar se llama Beulah. Es una placentera y amable Sombra/ Donde no hay disputa, debido a aquellos que Duermen"4 (32). Bloom sostiene que las fuentes que inspiran este espacio de indiferenciación "no son esotéricas; de hecho, no hay aspectos relevantes en Blake que necesiten buscarse en esos baldíos de la literatura, las tradiciones ocultas y teosóficas" (Visionary 16). Concluye que "Beulah es hebraica y protestante, en una tradición protestante de inconformismo que acentúa la Luz Interior" (16). El crítico antepone un sesgo que parece perfectamente legítimo, no solo desde un punto de vista hermenéutico, sino

\footnotetext{
Con este término intentamos establecer el afecto, en el sentido etimológico de inclinación y apego, que percibimos en los trabajos de Blake hacia la imaginación. Para los románticos ingleses, esta facultad es en sí misma, como el pensamiento metódico o instrumental, un modo de hacer que el mundo comparezca ante el sujeto. Por otro lado, el carácter "filoimaginal" que anima la visión blakeana nos retrotrae a un espacio fundacional, a los "cantos de la inocencia", anteriores al abrazo "filosófico" con la realidad.

$4 \quad$ Las traducciones de las fuentes primarias y textos críticos en inglés corresponden al autor del artículo.

"There is a place where Contrarieties are equally True:/ This place is called Beulah, It is a pleasant lovely Shadow/ Where no dispute can come, Because of those who Sleep".
} 
como parte de su propia visión de mundo. Sin embargo, al desestimar los aportes teosóficos, asociando a Beulah exclusivamente con la cultura judeocristiana, este espacio queda supeditado a un ethos singular, y no plural o expansivo, como sugiere la obra de Blake ${ }^{5}$.

Sus trabajos literarios y visuales enfatizan una configuración multiforme de la realidad. Además de la tradición judeo-cristiana, convergen una visión imaginativa y una mitología idiosincrásica que recrean el mundo blakeanamente, según la disposición creativa del autor. Por cierto, Beulah remite a un hebraísmo y protestantismo que redice sus propias bases calvinistas, algunas de ellas decididamente maniqueas. Pero a partir de esa fundación, los escritos y textos iluminados se proyectan a una región que sobrepasa el Libro de Isaías en el Antiguo Testamento. Como mencionamos, Blake elabora una poética expansiva que abraza la contemplación imaginativa del mundo, incluidas sus fuentes bíblicas, permitiendo la emergencia de un espacio "filoimaginal". Esta poética recorre sus textos proféticos, y también sus reflexiones en prosa, haciéndose consciente de sí misma. En el fragmento VI de No existe una religión natural I, leemos: "Los testamentos judíos y cristianos son una derivación original del genio poético" (Poems 237), declaración que acentúa una génesis expresiva anterior a la cosmovisión religiosa. A continuación, insiste que "así como todos los hombres son iguales (aunque infinitamente diversos), también todas las religiones, y todos los similares tienen un origen. Ese origen es el hombre verdadero, encarnación del genio poético" (237). La labor de este genio no desea exégesis o filosofías, sino una poiesis, en su sentido más amplio.

En Identidad, otra reflexión iluminada en prosa, Blake señala que "el mundo de la imaginación es infinito y eterno, mientras que el mundo de la generación o vegetación es finito y temporal" (Poems 231). Si las religiones "naturales" no existen, entonces toda religión sería fruto del genio poético y estarían, por lo tanto, subordinadas a una esfera inclusiva e imaginal. Estas relaciones son consistentes con la personificación de los rasgos procreativos de Beulah, representativos de una imaginación espiritualizada y eterna. Más adelante veremos que, en la poesía de Whitman, la procreación es signo de un impulso telúrico y sexual que anima la naturaleza, y que al igual que en

\footnotetext{
Visualizo la obra de Blake como una compleja constelación donde confluyen su pensamiento crítico, sus poemas y textos iluminados, la ejecución material de sus trabajos y, por cierto, su imaginación poética.
} 
Blake, se proyecta desde un estado vegetativo a otro inmaterial. "Beulah se crea siempre en la Eternidad; apareciéndose/ A los habitantes del Edén, a su alrededor y por todos lados"6 (32), afirma el hablante en Milton. Y las "colinas bañadas con las sombras de la luna" (32), por ejemplo, remiten al influjo nocturno que incita la imaginación. El romanticismo del siglo XIX, en cambio, tenderá a escuchar con mayor detención a las hijas de Beulah, "Musas que inspiran la canción del poeta"8 (1). Contrariamente a lo esperado, las visiones bellas y portentosas ocurren a plena luz de la noche. "De acuerdo a Blake", Beulah es también "la emanación del Edén, es decir, su forma exterior y femenina" (Bloom, Visionary 21). Esta proyección aparece a los habitantes de Beulah como "un niño en el regazo de su madre,/ Abrazado con amor y piedad y dulce compasión"9 (32).

Beulah, en tanto paradigma de la imaginación visionaria, refleja la fluidez e integración de un mundus imaginalis. La evocación de sus rasgos en los poemas proféticos y en los Cantos de inocencia deja, además, huellas indelebles. Una de ellas se refiere al carácter nutricio y placentero de la Imaginación, que los versos acentúan con delectables adjetivos. Beulah es descrita como una "pleasure lovely Shadow", prodigando a los Hijos del Edén "a mild \& pleasant Rest", un descanso placentero y sereno. El tipo de placer que se desliza en estas imágenes no es, por cierto, de orden sensual. Beulah insta una muerte vegetativa para el renacimiento de las imágenes espirituales, debilitadas por la experiencia. Desde aquí es posible asociar a Beulah con un espacio uterino. Los términos "pleasure" (placer) y "pleasurable" (placentero) provienen del latín "placere" (gustar y agradar), y su raíz griega "plax" (plano) significa placenta (Watkins 70). Este órgano intermediario y gestacional surge, entonces, como una metáfora que permite leer Beulah en consonancia con su naturaleza conectiva, un umbral "que posibilita el tránsito desde lo terrenal a lo espiritual, [acercándonos] al reino de la Eternidad: la imaginación" (Picón, "Beulah” 185). Una visualización uterina de Beulah

\footnotetext{
"Beulah is evermore created around Eternity; appearing/ To the Inhabitants of Eden around them on all sides".

"Beulah's moony shades \& hills".

"Daughters of Beulah! Muses who inspire the Poet's Song".

"As the beloved infant in his mother's bosom round incircled/ With arms of love \& pity \& sweet compassion".
} 
también es pertinente con su feminización, presente tanto en la visión de Blake como en el texto bíblico que la inspira ${ }^{10}$.

Esta intermediación gesta, a su vez, la anhelada fusión de los opuestos en un "útero" imaginal. La simbiosis de la semilla y el huevo; la unión de principios masculinos y femeninos; y la erótica del cuerpo vegetativo y el espiritual -que Emerson y Whitman traducen en clave tanscendentalistaconstituyen la restauración de una existencia pensada en fragmentos. Al respecto, y desde enfoques cognitivos y simbólicos al arte, lo imaginal en tanto "matriz" también se concibe como un "receptáculo, ambiente en el que se recogen las presencias de todas las cosas, o las huellas de su transmutación" (Rodríguez 37). Por otra parte, Blake ya manifiesta en sus cartas la unión de fuerzas esenciales en su trabajo artístico: "la Imaginación no es un estado: es en sí misma la presencia humana. Y el amor se transforma en un estado cuando se divide de la imaginación" (Cit. en Maclagan, xii).

Como hemos dicho, las imágenes en los textos de Blake construyen el espacio imaginario de Beulah a partir de una fuerza gestacional. La placidez ${ }^{11}$ y alumbramiento de este espacio, sin embargo, se interrumpen con el canto urizeniano de la experiencia. Urizen, y el libro que Blake le dedica en 1794, son decidores. Su representación visual, de impronta senil, pero robusta, concuerda con el envejecimiento de la Razón en sistemas newtonianos y cartesianos. En sentido alegórico, Urizen sería como el niño extraviado en los Cantos de inocencia que, a diferencia suya, no logra reunirse con su madre, es decir, con el cuerpo imaginal ${ }^{12}$. O como el infante sumido en el desencanto urbano en "Londres" que hace oídos sordos a su desesperación. Este poema actúa como complemento indispensable de la inocencia y, además, como índice de racionalización que nos acerca al tiempo de William Blake. "En esos años", indica Paz, "el paisaje pastoral de Inglaterra comienza a cambiar, y valles y colinas se cubren con la vegetación de hierro, carbón, polvo y detritus de la industria. Blake llama a los telares, minas, fraguas y herrerías 'fábricas satánicas', y 'muerte eterna' al trabajo de los obreros. Blake: nuestro contemporáneo” (63).

10 'Nunca más te llamarán Desamparada, ni tu tierra se dirá más Desolada; sino que serás llamada Hefzi-bá, y tu tierra, Beula; porque el amor de Jehová estará en ti, y tu tierra será desposada" (696, Isaías, 62:4). "placenta".

Uso el término desde la derivación propuesta anteriormente: "pleasant", "placentero", Aludo a "The Little Boy Lost" y "The Little Boy Found". 
En 1800 el mismo poeta reconoce, en un viaje en el que migra de la ciudad al campo: "Algo realmente importante que he logrado con mi venida aquí, y que significa un gran consuelo, es esto: he ordenado mis fragmentadas ideas sobre el arte, que en medio de la confusión de Londres había olvidado casi por completo" (Cit. en Maclagan viii). A diferencia de los paisajes urbanos en Whitman, tan vitales como los campestres, el espacio citadino en Blake es signo de abatimiento. "Errante transito calles censadas,/ Cerca del fluir del censado Támesis"13 (Poems 76). El adjetivo "chartered", que traducimos como "censadas", induce una gobernabilidad cartográfica del espacio. Las calles ya se han incorporado a una vigilancia hegemónica. Interesa notar que este logos reifica también la naturaleza, representada por la corriente del río. Sobre los rostros se inscriben, además, "marcas de cansancio, marcas de infortunio" 14 (76), como si fuesen territorios cartografiados. El hablante oye en los gritos de los adultos y en el llanto de los niños "las cadenas forjadas por la mente" (76), vale decir, los potentes ecos de la obra de Urizen.

La última estrofa es particularmente alusiva. "A medianoche, escucho en las calles/ Cómo la maldición de la joven prostituta/ Rompe las lágrimas de un recién nacido, / Y cierne con plagas la unión de los esposos"15 (77). Creo factible ver en la imagen de esta joven un nexo con la pintura The Whore of Babylon (La Ramera de Babilonia, 1809), a través de la cual Blake habría criticado el expansionismo imperial de Inglaterra durante el siglo XVIII ${ }^{16}$ (Rowland 307). En el Libro del Apocalipsis, la Ramera posee una función que admite, por un lado, la degradación o término de un ciclo, y el advenimiento de otro, el salvífico encarnado en Cristo. Como sugerimos antes, y relevando una poética de innovación, Blake acciona una exégesis imaginativa de las Escrituras. En el contexto desacralizado de la ciudad, la prostituta profiere una revelación muy distinta de la bíblica. Anuncia la imposibilidad de que el infante, o una Imaginación recién nacida, se acunen

13 "I wander through each chartered street,/ Near where the chartered Thames does flow".

14 "Marks of weakness, marks of woe".

15 "But most, through midnight streets I hear/ How the youthful harlot's curse/ Blasts the new-born infant's tear,/ And blights with plagues the marriage-hearse".

16 De acuerdo a Rowland, "el Apocalipsis ofrece a Blake, un profeta de estilo único, la inspiración para desafiar la apatía política de su tiempo, y lo que él mismo consideraba como una relación blasfema entre religión y violencia o, según sus palabras, 'la religión oculta en la guerra"” (308). 
entre los sollozos y gritos que desconciertan al hablante del poema. En su versión burocrática e institucional, Londres se ha convertido en metrópolis, ciudad-matriz colonizadora. Y al hacerlo, renuncia al espacio matricial de la experiencia trascendente, y a constituirse en el espacio "placentero" de una imaginación visionaria.

\section{EMERSON: UN OJO TRANSPARENTE EN LA CRISIS DEL TIEMPO}

Cuando la mente fluye en y a través de lo más elevado e inescrutable, la metamorfosis es posible...

R. W. Emerson, "El poeta"

La obra del escritor y filósofo R. W. Emerson debe entenderse en el contexto del transcendentalismo en Nueva Inglaterra y, como hemos propuesto, en conexión con el trabajo visionario de Blake. El movimiento trascendentalista remece a una sociedad protestante, predominantemente calvinista, y con fuerte arraigo en el puritanismo. Si bien algunos enfoques explican el transcendentalismo como una deriva del romanticismo inglés en tierras americanas, críticos como Malcolm Bradbury y Richard Ruland acentúan su carácter insólito, y como la manifestación más vigorosa de un "American Naissance" (104), cota cero desde la cual emerge una imaginación literaria auténticamente americana. Publicado en 1836, el ensayo Naturaleza [Nature] abre este recorrido, sentando las bases filosóficas del movimiento. Cabe notar que es un género referencial, y no ficticio, el que inaugura esta inflexión en la historia literaria de los Estados Unidos. Este hecho no debiese sorprender, si pensamos que uno de los recursos más estimados por las sociedades coloniales que aspiran a su independencia cultural es, precisamente, el ejercicio de "ensayarse" en imaginarios otros a los concebidos por una voluntad de poder.

En la introducción a Naturaleza, Emerson percibe la crisis de su tiempo en el carácter pusilánime de su generación, que califica de "retrospectiva"17

17 Emerson insiste en esta idea en "Self-Reliance" (1841), ensayo que invita a confiar en el ser interior. "Cuando nos expresamos lo hacemos a medias", admite, "como si nos avergonzara la idea divina en nuestro interior" (1108). Y en otro pasaje: "El hombre se ha vuelto tímido y apologético; ya no camina derecho; no se atreve a decir 'pienso', o 'soy', 
(1040). En sentido amplio, la suya es una edad retrógrada y nostálgica. "Escribimos biografías, historias y crítica. Las generaciones pasadas se encontraron cara a cara con Dios y la naturaleza; nosotros, a través de sus ojos" (1040). Es a partir de esta crisis que el autor esboza sus reflexiones. “¿Por qué no podríamos también nosotros gozar una relación original con el universo? ¿Por qué no construir una poesía y una filosofía iluminadas, y no tradicionales, y una religión revelada directamente a nosotros?" (1040). Imágenes clave son iluminación, o "insight", y revelación, ya que remiten al halo numinoso, a la visión interna que transforma lo sensible en portal hacia lo invisible.

La sensibilidad y la sensualidad son, no obstante, indispensables. Además de constituirse en medios, integran, junto a lo invisible e insondable, un concierto donde las oposiciones racionales se disuelven. A través de sus representaciones pictóricas y visibles, el paisaje detenta un fuerte significado estético. Emerson, sin embargo, traspasa esta materialidad y, en un gesto transcendental, construye paisajes interiorizados, también profusos en los poemas de Whitman. Al respecto, escribe: "El encantador paisaje que vi esta mañana consta de unas veinte o treinta granjas, pero ninguno de sus dueños posee el paisaje. Hay una propiedad en el horizonte que ningún hombre posee, excepto aquel cuyo ojo puede integrar todas las partes, el poeta" (1042). En "El poeta" (1841) vuelve sobre este principio platónico cuando observa que "un segundo y maravilloso valor aparece en los objetos, mucho mejor que su valor primario; como la tensa cuerda del carpintero que, si acercamos el oído, es musical en la brisa" (1153). A través de esta ruptura de las apariencias, de esta mirada visionaria consciente de los pliegues ocultos en cada ser y objeto, Emerson se aproxima al deleite de "una relación original con el universo", que equivale al retorno a un espacio imaginal.

Es necesario señalar que los escritos iluminados de Blake también perfilan paisajes y elementos de la naturaleza. Sin embargo, percibimos una distinción importante. Mientras en los trabajos del visionario inglés estas referencias aluden a textos sagrados, y a imágenes míticas y arquetípicas, los trascendentalistas optan por la celebración del paisaje vernáculo, su flora y fauna. A diferencia del exotismo del tigre blakeano, por ejemplo, la belleza del bisonte, la fértil extensión de praderas, bosques y costas, y la dignidad

sino que cita a algún santo o sabio. Se avergüenza frente a las hojas de hierba y el soplo de las rosas" (1117). 
de los pueblos originarios constituyen el acervo que se integra a la visión transcendental. "The Rhodora" (1839) es un poema breve en el que Emerson admira la simple belleza de esta flor silvestre, autóctona de las quebradas de Nueva Inglaterra. En una visión epifánica, el hablante pregunta, “¿De dónde vienes? ¡Oh, rival de la rosa!/ Nunca pensé preguntar, nunca supe;/ Pero en mi ignorancia, supongo que/ El mismo Poder que me trajo aquí/ también te creó a ti" ${ }^{18}$ (1190), generando una afinidad, o una correspondencia analógica, entre el hombre, la naturaleza y una voluntad trascendente.

Gradualmente, y desde el reencuentro de lo visible e invisible, podemos leer las reflexiones de Emerson en sintonía con una placenta imaginal, ya sedimentada en la poesía de Blake. Un nodo central en la escritura emersoniana, en tanto tema y metáfora, es la cita de imágenes especulares con las que interroga su relación, única y variada, con el universo. El siguiente pasaje de Naturaleza refleja la apertura a esta esfera imaginal: "Cuando estoy en contacto con la tierra, mi cabeza bañada por el aire ligero, y erguido hacia el espacio infinito, todo egoísmo desaparece. Me convierto en un ojo transparente. Soy nada. Lo veo todo. Las corrientes del Ser Universal circulan a través mío; soy parte o una partícula de Dios" (1043). El ojo germina así un "insight" que triza el velo de las apariencias, vislumbrando el paso de lo finito a lo infinito.

Las imágenes y metáforas ópticas que aluden a la emergencia de una visión interiorizada, pero al mismo tiempo espaciada en un universum espiritual, alientan una forma, la esférica. Blake alude a ella con frecuencia en Milton: "La naturaleza del infinito es ésta: Cada existencia posee su/ Propio vórtice; y cuando un viajero a través de la Eternidad/ Ha pasado ese Vórtice, siente que éste rueda hacia atrás bajo sus pies/Y se convierte en una esfera, como un sol,/ O como una luna, o como un universo estrellado,/ Mientras sigue adelante en su maravilloso viaje en la tierra" 19 (11). En perspectiva emersoniana, por su parte, el poeta visionario deviene ojo y mirada al mismo tiempo, transformación que altera al poeta en el mundo y su percepción de lo eterno. Deja de ver el entorno con las coordenadas topográficas de costumbre; permitiendo que la

18 "Why thou wert there, O rival of the rose!/ I never thought to ask, I never knew; But in my simple ignorance, suppose/The same-self Power that brought me there brought you".

19 "The nature of infinity is this: That every thing has its/ Own Vortex; and when once a traveller thro' Eternity/ Has passed that Vortex, he perceives it roll backward behind/ His path, into a globe itself infolding, like a sun,/ Or like a moon, or like a universe of starry majesty,/ While he keeps onwards in his wondrous journey on the earth". 
planicie se abra a la esfericidad visionaria, en cuyo centro incluso los afectos convencionales se deshacen. Así, cuando se "es un átomo de la divinidad", es decir, cuando se asume la condición esférica de la existencia y la reunión de los opuestos, hasta "el nombre del más querido amigo suena extraño y accidental. Ser hermanos, ser conocidos; maestro o siervo, todo ello es un pasatiempo y una molestia" (1043).

Esta mirada ulterior insufla toda la escritura de Emerson. "El poeta", señala, "conoce astronomía, química, el mundo vegetal y el animal”, pero no se fía de ellos, "que interpreta como signos" ("Poeta" 1156). Esta sospecha, no metódica, sino intuitiva, estimula en Whitman el uso de recursos que reflejan, en el espacio poético, la trascendencia imaginal. Así, otro ángulo de esta visión acentúa las apariencias que nos alejan del Ser Universal. Lo que fascina a Emerson, tanto como a Blake, es "la inaccesibilidad de los pensamientos", por cuanto en esa lejanía yace una experiencia "maravillosa" (1162). Esta mirada interior se expresa por medio de la "Imaginación, que es una forma superior de visión" (1158). Y para alcanzarla es necesario que el poeta se done "al aura divina que respira a través de todas las cosas" (1159). Sobresale una autenticidad que se antepone a un orden circunstancial. La experiencia imaginal comportaría siempre una "lejanía, no importa lo cercanos que creamos estar" ("Poeta" 1162). De aquí el "amor por los poetas, inventores que en odas o acciones, legan un pensamiento nuevo. El poeta rompe nuestras cadenas y nos conduce a un nuevo espacio" (1162). Como hemos propuesto, la imagen de un "ojo transparente" y este espacio poético pueden leerse como figuraciones auráticas de un mundus imaginalis que inspira la actividad visionaria, esta vez en los paisajes campestres de Nueva Inglaterra.

Para comprender estas visiones, y de acuerdo a Corbin, se requiere "un esfuerzo para superar el 'reflejo agnóstico' prevalente en Occidente, responsable por el divorcio entre pensamiento y ser" (4). También es necesario acotar que, sin excluirla, Emerson no privilegia una noción judeo-cristiana de Dios. Confía, más bien, en una energía irresistible, ecuménica y transreligiosa. La imagen líquida de una corriente circulatoria da cuenta de esta presencia que inunda el espíritu humano. Considerando las ideas de Corbin, el mundus imaginalis implicado en la visión emersoniana permite no solo una transición, sino la confluencia e indiferenciación de lo corpóreo y lo espiritual. En efecto, para el pensador francés este mundus, que los teósofos del Islam llaman "el octavo clima" o "alam al-mithal", es "un mundo intermediario donde habitan los espíritus después de su tránsito en el mundo terrestre y natural; mundo en el 
que subsiste la forma de nuestros pensamientos y deseos; presentimientos, acciones y obras realizadas en la tierra" (6).

En este sentido, los aportes de Corbin son fundamentales, pues instan una relectura del modo en que Emerson y Whitman conciben las relaciones entre lo finito y lo infinito, lo mesurable y lo inconmensurable. No en términos dicotómicos, sino convergentes: "el poeta, que reúne las cosas de la naturaleza y del Todo [...], dispone muy fácilmente de los hechos más incompatibles", sostiene Emerson ("El poeta" 1155). En conjunto, las contribuciones de Emerson y Corbin son afines, a pesar de la latitud de sus espacios discursivos. Ambos pusieron a disposición de audiencias occidentales textos de la tradición filosófica y religiosa oriental ${ }^{20}$. Emerson sostiene que el verdadero poeta no es el maestro del estilo, atribuible a una rúbrica personal, sino quien expresa verdades trascendentes en sincronía con la disolución del yo, como sugieren los textos sagrados hindúes. "Saadi" (1842), "Hamatreya" (1846) y "Brahma" (1856) son algunos poemas suyos que siguen esta dirección.

En la introducción a este trabajo indicamos que la emergencia de una poética visionaria surge en tándem con la percepción de un tiempo en crisis. Es el tiempo de la modernidad que, desde mediados del siglo XIX, impacta a los Estados Unidos con la masificación de los centros urbanos, la anexión del territorio de Texas, los debates abolicionistas y, eventualmente, el pasmo de la Guerra Civil. Como vimos, la poesía de Blake también está ligada a este desgaste histórico. De esta forma, el poeta sería el registro sensible que, como un sismógrafo, y según Edgar Lee Masters, absorbe e interpreta los cambios sociales. La poesía visionaria, en general, posee esa cualidad. Por un lado, se proyecta en la eternidad de una promesa, sea ésta utópica o mesiánica; por otro, es atenta hija de su tiempo y los sucesos que sobrevienen.

Apelando al poeta vital que yace en cada individuo, Emerson exhorta a sus lectores a convivir entre lo contemporáneo y lo extemporáneo. "Confía en ti mismo: cada corazón vibra con esa cuerda de metal. Acepta el lugar que la divina providencia te ha designado, la compañía de tus contemporáneos, la

$20 \quad$ Además de los filósofos alemanes y los poetas románticos ingleses, "los trascendentalistas estaban influidos por Platón, Plotino, los platónicos de Cambridge del siglo XVIII, los escritos de Confucio, las Upanishads y el Bhagavadgita, diversos tipos de budismo, Thomas Kempis y Pascal" (Conn 98). Emerson alude a estas fuentes en sus ensayos con regularidad. Sin embargo, es en la sección "Escrituras étnicas" de El Dial, medio de difusión del pensamiento trascendentalista, donde Emerson comparte sus interpretaciones del Bhagavad Gita y de otros textos sagrados chinos y persas. 
conexión de los eventos. Los grandes individuos confían, como niños, en el genio de su tiempo" ("Self-Reliance" 1108). Concluye: "Alcanzada ya cierta edad, debemos aceptar con integridad nuestro destino trascendente" (1109). El tiempo que Emerson visionariamente imagina es íntegro y concebido en integridad; el altruismo del hombre, representado por el pensamiento digno de una mente no conformista (1109), percibe en la infinitud del Todo un sentido de correspondencia. Tiempo que rebasa sus propios límites, pero aún no desquiciado. La Guerra Civil y sus consecuencias, no obstante, confirmarían el arribo a ese desquicio que el transcendentalismo emersoniano no logró vislumbrar.

\section{WHITMAN: COMUNIDAD VISIONARIA Y GUERRA CIVIL}

¿Quién conoce el misterio de la visión?

Otros sentidos se explican a sí mismos, pero la visión resiste los hechos y anticipa los eventos del mundo espiritual. Walt Whitman, prefacio a Hojas de Hierba

Así como la inocencia y la experiencia en las canciones de Blake establecen una reciprocidad, las Hojas de hierba (1855) dejan escuchar al menos dos registros complementarios; uno trascendental, otro crepuscular. De modo similar a los escritos de Blake y Emerson, los cantos visionarios de Whitman avanzan conscientes de su lugar en el tiempo y el espacio. Su vitalismo no es adánico; coexiste con crisis pre y posbélicas que aquilatan un sentido trascendente de la historia. "Nunca hubo más orígenes que hoy,/ Ni más juventud ni edad que hoy, / Y nunca habrá más perfección que hoy, / Ni más cielo o infierno que hoy"21 ("Poema 2", 1728). La aparente contradicción de una historia y un materialismo cultural trascendentes encuentra en Canto a mí mismo un espacio de correspondencia. La enunciación está sujeta a un "hoy" que, como vórtice o espacio imaginal, absorbe y refleja experiencias

$21 \quad$ Las citas provienen de la edición de 1855 de Leaves of Grass. "There was never any more inception than there is now,/ Nor any more youth or age than there is now,/ And will never be any more perfection than there is now,/ Nor any more heaven or hell than there is now". 
solidarias. En este presente visionario la oposición maniquea deja de ejercer su cometido: dividir y racionalizar. Cabe preguntamos, entonces, hasta qué punto el impulso visionario en la poesía de Whitman, y en especial los vórtices que ella genera, se convierten en contra-dispositivos que interpelan a la modernidad. Giorgio Agamben define un dispositivo como "cualquier cosa que tenga la capacidad de capturar [...] y asegurar los gestos, las conductas, las opiniones y los discursos de los seres vivientes" (18). Concluye que la "profanación es el contra-dispositivo que restituye al uso común lo que el sacrificio había separado y dividido" (22). El término nos parece pertinente, más aún si la religión es "aquello que sustrae cosas, lugares, animales o personas al uso común y las transfiere a una esfera separada" (22). Resulta evidente que la modernidad realiza, desde el ámbito secular, la misma acción. La imaginación romántica sería, desde este punto de vista, un acto profano y restaurativo.

La solidaridad entre la imaginación visionaria y las crisis de la modernidad genera una unidad de sentido entre ámbitos aparentemente disímiles. Si una de estas crisis se percibe, tanto en Blake como en Emerson, en términos de una relación pusilánime del hombre con su presente, en Whitman la crisis se asocia a una nueva forma de concebir la comunidad. No como utopía "desobrada", sino como experiencia encarnada en la construcción democrática $\mathrm{y}$, por lo tanto, sujeta a las discontinuidades del devenir histórico: “el genio de los Estados Unidos no es mejor ni más intenso en sus autoridades o leyes [...], sino, como siempre, en la gente común" ("Prefacio" 2). Sobre este aspecto, Jean-Luc Nancy sugiere que la cultura moderna occidental aun no transita, en términos políticos efectivos, por una comunidad. "[S]i es cierto que la humanidad conoció (o conoce aún, fuera del mundo industrial) vínculos sociales completamente distintos de los que nosotros conocemos, la comunidad no ha tenido lugar según las proyecciones que hacemos de ella" (29). ¿Hasta qué punto la comunidad, o el clinamen del individuo" (Nancy 17), tiene lugar en el trabajo visionario de Whitman?

En el prefacio de 1855 a Hojas de hierba, Whitman escribe: "No somos solo una nación, sino una populosa nación de naciones. Somos una acción unida por vínculos superiores a los detalles, que se mueve magníficamente en grandes masas" (3). La comunidad se encarna en un acto colectivo. El catálogo de prácticas comunales abre una genealogía que, a diferencia de la bíblica, confía primeramente en la gente: "el carácter noble del joven mecánico y de todos los trabajadores y trabajadoras americanos... la iniciativa y amistad y entusiasmo de todos -la perfecta equidad de hombres 
y mujeres... la gran amatividad -el movimiento fluido de la población- las fábricas y la vida mercantil y las maquinarias" (4). Si en la poesía de Blake el progreso industrial y urbano significa alienación de la voluntad visionaria, en Whitman estimula congregación popular y el nacimiento de "una literatura nacional, especialmente de poemas arquetípicos. Por sobre el territorio, una gran literatura original de seguro será la justificación y el soporte (en algunos casos el único) de la democracia americana" (Democratic Vistas 6).

Este vigor comunitario se problematiza si consideramos los matices crepusculares en Canto a mí mismo. Desde el comienzo, el poemario presenta una exuberante energía seminal. "El bien y el mal se mecen en mí, hablo sin temor,/ Naturaleza incontenible, plena de energía original"22 ("Poema 1", 1727); "Impulso, impulso, impulso/ Siempre el impulso procreador del mundo"23 ("Poema 3", 1728). Sin embargo, y a medida que el canto avanza, el amanecer de este magnetismo erótico se entrecruza con imágenes disruptivas. La figura de una tierra nutricia y ágrafa -excepto por la locución poética-se intercepta con la modernidad y sus heraldos crepusculares: la desacralización del mundo, la esclavitud y la guerra de secesión. Bajo estos signos, el poemario Golpes de tambor (Drum-Taps) amerita leerse no como el revés tanatológico de las alusiones (homo)eróticas en Canto a mí mismo y Cálamo, sino como su balance, explorando así la reciprocidad de los opuestos que recomiendan, en distintos tonos, los poetas de este estudio. Surgen nuevas visiones colectivas que expresan, al mismo tiempo, una consciencia de disolución.

Whitman vislumbra de este modo un horizonte de transformaciones que ofuscan y, al mismo tiempo, exacerban la creación de una democracia inédita, fusión de cuerpos en una camaradería erótica. "Las batallas, el horror de la guerra fratricida, la fiebre de noticias inciertas, los eventos inesperados;/ Llegan a mí día y noche, y desaparecen", declara el hablante, y en seguida reconoce, "Pero no son quien soy"24 ("Poema 4", 1730). No lo representan, porque su "yo" es adhesivo, fraterno. Como cuando cobija el cuerpo inerte de un soldado en el campo de batalla: "En una frazada cubrí a mi compañero,/ Dejándola con cuidado sobre la cabeza, y con suavidad bajo sus pies;/ Y allí, entonces, y bañado por el sol del amanecer, a mi hijo

22 "I harbor for good or bad, I permit to speak at every hazard,/ Nature without check with original energy".

23 "Urge and urge and urge,/ Always the procreant urge of the world".

24 "Battles, the horrors of fratricidal war, the fever of doubtful news, the fitful events; / These come to me days and night and go from me again,/ But they are not the Me myself". 
en su sepultura, en su ruda sepultura, acuné"25 (Drum-Taps 279). En otros momentos, la subjetividad del poeta se desprende, al modo de partículas, de una configuración ominosa, integrándose al canto comunal. "Me celebro y canto a mí mismo,/ Mis creencias son también tuyas,/ Ya que cada uno de mis átomos te pertenece a ti" ${ }^{26}$ ("Poema 1", 1727). Este clinamen, o desvío espontáneo que busca, como diría Emerson, la metamorfosis de la individualidad al amparo de otros, es clave en la poética visionaria de Whitman. A través de esta fuga el poeta deviene "Camarada de los californianos, camarada de los que habitan el oeste norteño, (amante de sus proporciones,)/ Camarada de balseros y mineros, camarada de todos los que saludan de mano,/ y gozan comer y beber" 27 ("Poema 16", 1740).

A partir de este ámbito crepuscular apreciamos una condición visionaria que se expresa en un vórtice imaginal de correspondencias. La crisis insta una visión y ésta, a su vez, permite al poeta leer su tiempo como si fuese un "jeroglífico" ("Poema 6", 1731), donde lo "invisible se palpa en lo visible"28 ("Poema 3", 1729). Volvamos ahora al prefacio de Hojas de hierba. "El mayor desafío de quien aspire ser un verdadero poeta es el presente", afirma Whitman, "y si no es capaz de sumergirse en su tiempo como en vastas mareas oceánicas [...], será mejor que espere” (7). Esta noción de cercanía es análoga a la de Emerson sobre el valor de lo contemporáneo, pero adquiere lustre propio cuando Whitman acentúa que el poeta "debe convertirse en la edad transfigurada" (8). El paso de lo visible, el hoy, a lo invisible, la reconstitución de ese presente, marca en Whitman su tránsito por el territorio imaginal en Hojas de hierba. Es el inicio de una poética visionaria que Emerson, entusiasta, felicita como "el más extraordinario trabajo de ingenio y sabiduría que América ha creado hasta ahora"29 (345). "El poeta", continúa Whitman, "abre la eternidad que

25 "My comrade I wrapt in his blanket, envelop'd well his form,/ Folded the blanket well, tucking it carefully overhead and carefully under feet,/ And there and then and bathed by the rising sun, my son in his grave, in his rude-dug grave I deposited".

26 "I celebrate myself, and sing myself,/ And what I assume you shall assume,/ For every atom belonging to me as good belongs to you".

27 "Comrade of Californians, comrade of free North-Westerners, (loving their big proportions,)/ Comrade of raftsmen and coalmen, comrade of all who shake hands and welcome to drink and meat".

28 "[...] the unseen is proven by the seen".

29 Carta dirigida a Whitman el 21 de julio de 1855. Esta breve nota se incluye, junto a otra más extensa de agradecimientos a Emerson, en el apéndice a la segunda edición de Hojas de hierba de 1856. 
confiere similitud a todas las épocas y espacios y procesos, y a las formas animadas e inanimadas, y que es la unión del tiempo que se levanta desde su inconcebible infinitud en la turbulencia del presente" (8).

Observamos en esta apertura afinidades con la dimensión imaginal. Los trascendentalistas vinculan lo eterno al Ser Universal, una "facultad independiente de las limitaciones que nos rodean. El Espíritu abraza todas las cosas, y contradice la experiencia. Anula, de igual forma, el tiempo y el espacio. El Espíritu juega con el tiempo" (Emerson, "The Over-Soul" $\mathrm{s} / \mathrm{n}$ ). Las relaciones entre el trascendentalismo norteamericano y el mundus imaginalis se vuelven pertinentes, si admitimos la influencia de las teosofías orientales en el pensamiento de Emerson. Lo estipulado sobre el Espíritu, por ejemplo, se asemeja a la fuerza renovadora del mundus imaginalis, donde "las formas y figuras no subsisten como lo hacen las realidades empíricas del mundo físico [...], o del ámbito exclusivamente inteligible" (Corbin 6). Las formas germinan, en tanto reflejo y figuración de lo visible, gracias a la Imaginación, que sería la función cognitiva de aquel mundus, según Corbin.

Las reflexiones de Whitman sobre la labor del poeta en el prefacio y en el apéndice de la edición de 1856 de Hojas de hierba son cruciales. El creador "transforma su circunstancia presente en un pasaje que une el pasado con el futuro, y se compromete a la representación del instante" (8). Las formas aparentes, como el tiempo secular, son relevantes, por cuanto "[t]odas las verdades esperan en todas las cosas, / No apresuran ni resisten su nacimiento,/ [...]/ Lo insignificante es grande como todo lo demás,/ ¿Qué es más o menos que una caricia?)" 30 ("Poema 30", 1750). Además, estas formas articulan las visiones por medio de la palabra. Esta transfiguración origina vehementes exhortaciones: "Quédate hoy y esta noche conmigo y poseerás el origen de todos los poemas, $[\ldots]$ / Nunca más los muertos guiarán tu mirada, ni los espectros en libros,/ Tampoco yo guiaré tu mirada,/ Oirás de todos lados y por ti mismo"31 ("Poema 2", 1728).

¿Cuáles serían, en el espacio retórico de la poesía de Whiman, las formas aparentes que unen lo visible y lo invisible? El paralelismo, o la simetría

30 "All truths wait in all things, / They neither hasten their own delivery nor resist it,/ They do not need the obstetric forceps of the surgeon,/ The insignificant is as big to me as any,/ (What is less or more than a touch?)".

31 "Stop this day and night with me and you should possess the origin of all poems,/ $[\ldots] /$ You shall not look through my eyes either, nor take things from me,/ You shall listen to all sides and filter them from your self". 
sintáctica en y entre dos o más versos, consolidan en el plano escritural el pacto entre lo sensible e inmaterial, lo sanguíneo y espiritual. "Clara y dulce es mi alma, y claro y dulce es todo aquel que no es mi alma"32 ("Poema 3", 1729). Sobresale en estos diseños espejeados la anáfora, que también insiste en el ansiado encuentro de las divergencias: "Entre sombras avanzan semejantes opuestos, siempre sustancia y origen, siempre sexo,/ Siempre identidades abrazadas, siempre diferencias, siempre un soplo de vida" 33 ("Poema 3", 1728). Señalamos que una mirada ulterior ilumina las reflexiones de Emerson. Whitman la traduce en imágenes que, a diferencia de las emersonianas, resuenan con efectos sinestésicos; la visión se desprende de su órbita y comienza a palparse, escucharse y gustarse. Desde esta perspectiva, la sinestesia funciona como una construcción verbal visible que, a su vez, leemos como analogía de un espacio imaginal que trasciende la historicidad de la comunidad democrática. De este modo, las crisis de la modernidad que hemos discutido en este estudio, desde Blake a Whitman, dejan de actuar fragmentariamente, integrándose a una comunidad visionaria que alienta la democracia sui generis donde se entrelazan la razón y la imaginación románticas.

\section{CONCLUSIONES}

Antes de su inscripción en procesos históricos, o de su historicidad, varios temas explorados en este trabajo tuvieron arraigo en mitos fundacionales. Fue en un momento posterior, con el asomo de una cultura moderna, que experiencias como el (des)encuentro entre myhtos y logos, la percepción de un tiempo desamparado por los dioses y la relación visionaria del sujeto con la naturaleza -y consigo mismo- comienzan a tematizarse. Al respecto, uno se sentiría inclinado a pensar que el ingreso de estas experiencias en los registros escriturales comporta un desgaste, en particular con su secularización en el género de la novela inglesa de los siglos XVII y XVIII. Sin embargo, y aceptando la pérdida de su irrepetible singularidad, también es cierto que estas experiencias se convierten, a partir de sus narraciones modernas, en objetos de exploración, y adquieren la posibilidad de interpretarse desde las dinámicas críticas del discurso.

32 "Clear and sweet is my soul, and clear and sweet is all that is not my soul".

33 "Out of dimness opposite equals advance, always substance and increase, always sex,/ Always a knit of identity, always distinction, always a breed of life". 
Estas narraciones, desde luego, no comprometen solo a la prosa, sino, como hemos visto, la poesía visionaria de William Blake, R. W. Emerson y Walt Whitman. Al respecto, el discurso crítico que gira en torno a ella se ha construido principalmente desde una separación, centrándose, por un lado, en el prerromanticismo de Blake, o el transcendentalismo de Emerson y Whitman. Este trabajo intentó, por el contrario, enfatizar la convergencia de estas distintivas expresiones de la imaginación visionaria a la luz del mundus imaginalis. Desde aquí emergen distintas visualizaciones de este espacio arraigadas en poéticas que delatan, no obstante, una crítica de la modernidad. Así, la solidaridad entre la imaginación visionaria y las crisis de la modernidad genera una unidad de sentido entre ámbitos aparentemente disímiles. No solo las obras de los poetas oscilan entre un mundo visionario y otro desencantado, sino que su propio pensamiento resiste, por así decirlo, el férreo radicalismo de Urizen. De algún modo, ese pensamiento fue el que orientó, en términos de método o vía de lectura, el análisis de los trabajos seleccionados. Nuestra intención fue visualizarlos a contraluz de una cultura moderna que, ya en el siglo XVIII, deja entrever ostensibles fisuras.

Como indicamos en el marco teórico, la experiencia visionaria suele interpretarse como una transición, el paso que va de la historicidad del poeta a un espacio-tiempo inédito, enunciado en la tesitura del poema. Este estudio indaga ese trance, pero también en el hecho de que, debido a una consciencia de un tiempo en crisis, la visión de los poetas no enceguece en un mundus imaginalis, sino que sigue contemplando la marcha de la modernidad y sus ilusiones. Esta recomposición, en la visión de los poetas, implica erradicar disonancias, aspirando a la simetría de los opuestos, como sugieren "El tigre" de Blake y la felicitación al unísono al cuerpo y el alma en la poesía de Whitman.

Finalmente, un aspecto emergente que surgió a medida que se articulaban los trabajos en una lectura dialogada, fue la asociación del espacio imaginativo con una parte del cuerpo. La imaginación visionaria de Blake deviene placenta gestacional que origina la deseada fluidez, o la conjunción de los opuestos. Emerson, por su parte, se ocupa de la transparencia del ojo, que asimila la energía sensible y la refracta en un sentido de unión cósmica con el Ser Universal, donde "toda forma de egoísmo desaparece" (1043). Whitman, en tanto, dedica gran parte de su poesía a espiritualizar el cuerpo y a corporizar el alma, recordando que la visión trascendente no es aquella que sobrepasa la fisicidad, sino la que recompone el cuerpo escindido o fragmentado. Por lo mismo, Golpes de tambor, que lamenta una guerra fratricida inimaginable, expresa esta visión tan locuazmente como Canto a mí mismo y Cálamo. 


\section{BIBLIOGRAFÍA}

Agamben, Giorgio. ¿Qué es un dispositivo? Buenos Aires: Adriana Hidalgo, 2014.

Blake, William. Collected Poems. Ed. W. B. Yeats. London: Routledge, 2002.

Milton. The Prophetic Books of William Blake. Eds. E. R. D. Maclagan and A. G. B. Russell. London: A. H. Bullen, 1907.

The First Book of Urizen. The William Blake Archive. <www.blakearchive.org.> Acceso: 08 de marzo de 2019.

Bloom, Harold. The Visionary Company. A Reading of English Romantic Poetry. New York: Doubleday \& Company, 1961.

Bradbury, Malcolm y Richard Ruland. From Puritanism to Postmodernism. New York: Penguin Books, 1992.

Conn, Peter. Literatura norteamericana. Madrid: Cambridge University Press, 1998.

Corbin, Henry. Cuerpo espiritual y Tierra celeste. Madrid: Ediciones Siruela, 1996.

"Mundus Imaginalis or The Imaginary and The Imaginal". The Bahá'i Studies.

$<$ http://www.bahaistudies.net/> Acceso: 18 de enero de 2019.

Emerson, Ralph Waldo. Essays and Poems. En The American Tradition in Literature. Ed.

Sculley Bradley. New York: Grosset \& Dunlap, 1974.

"Letter to Walt Whitman". The Walt Whitman Archive. Eds. Ed Folsom y Kenneth

M. Price. $<$ http://www.whitmanarchive.org $>$. Acceso: 8 de febrero de 2019.

"The Over-Soul". The Works of Ralph Waldo Emerson. < https://www.rwe.org/>. Acceso: 30 de marzo de 2019.

Góngora, María Eugenia. "Escritura e imagen visionaria en el liber divinorum operum de Hildegard de Bingen”. Teología y Vida, Vol. XLVI (2015): 374-388.

Jackson, Virginia. “American Romanticism, Again”. Studies in Romanticism 55, (Fall 2016): 319-346.

La Santa Biblia. Revisada por Cipriano De Valera. Nashville. Tennessee: Holman Bible Publishers, 1990.

Masters, Edgar Lee. Emerson: el perdido espíritu americano. Buenos Aires: Losada, 2007.

Maclagan, E. R. y A. G. Russell. "Introduction". Milton. The Prophetic Books of William Blake. London: A. H. Bullen, 1907. 5-16.

Nancy, Jean-Luc. La comunidad desobrada. Madrid: Arena Libros, 2001.

Paz, Octavio. Los hijos del limo. Santiago: Tajamar Editores, 2008.

Picón, Daniela. "Beulah: intermundo, surrealidad. El territorio del subconsciente y los sueños en el mundo visionario de William Blake". Revista Chilena de Literatura 86 (2014): 177-197.

Visiones de William Blake. Itinerarios de su recepción en los siglos XIX y XX. Barcelona: Calambur, 2017.

Rodríguez, Martín. "Exponer lo imaginal: reproducir y representar". Arte, Individuo y Sociedad 22 (2010): 35-48. 
Rowland, Christopher. “Imagining The Apocalypse”. New Testament Studies, Vol. 51 (2005): 303-327.

Ruland, Richard y Malcolm Bradbury. From Puritanism to Postmodernism. A History of American Literature. New York: Viking, 1993.

Todorov, Tzvetan et al. El nacimiento del individuo en el arte. Buenos Aires: Nueva Visión, 2006.

Watkins, Calvert. The American Heritage Dictionary of Indo-European Roots. New York: Houghton Mifflin Harcourt, 2011.

Weber, Max. El político y el científico. México, D. F.: Universidad Autónoma de la Ciudad de México, 2008.

Whitman, Walt. Democratic Vistas. $<$ https://archive.org/details/democraticvista $>$. Acceso: 29 de marzo de 2019.

Drum-Taps. The Works of Walt Whitman. Hertfordshire: The Wordsworth Poetry Library, 1995.

Preface to Leaves of Grass. The Walt Whitman Archive. Eds. Ed Folsom y Kenneth M. Price. <http://www.whitmanarchive.org>. Acceso: 7 de febrero de 2019.

Song of Myself. The American Tradition in Literature. Ed. Sculley Bradley. New York: Grosset \& Dunlap, 1974. 